\title{
Unusual Complication Following Spinal Anesthesia for Caesarean Section
}

\author{
A. Antwi-Kusi*, W. Sam Awortwi, A. Serwaa Hemeng \\ Department of Anesthesia and Intensive Care, Komfo Anokye Teaching Hospital, Kumasi, Ghana. \\ Email: *antwikusi@yahoo.com \\ Received February $1^{\text {st }}, 2013$; revised April $2^{\text {nd }}, 2013$; accepted May $9^{\text {th }}, 2013$ \\ Copyright (C) 2013 A. Antwi-Kusi et al. This is an open access article distributed under the Creative Commons Attribution License, \\ which permits unrestricted use, distribution, and reproduction in any medium, provided the original work is properly cited.
}

\begin{abstract}
Spinal anesthesia involves the introduction of local anesthetics into the subarachnoid space leading to the loss of sensation of pain. Common complications following spinal anesthesia include hypotension leading to nausea and vomiting, failure of the spinal and post dural puncture. Other uncommon complications include high and total spinal and spinal haematoma. In this report the patient experienced uncontrollable jerking of the lower limbs, hypertension, arrhythmias and cardiac arrest refractory to resuscitation.
\end{abstract}

Keywords: Intrathecal; Tranesamic Acid; Convulsion; Arrhythmias

\section{Introduction}

Spinal anesthesia is a relatively safe regional anesthesia with few complications that can be easily managed. It involves the introduction of local anesthetic, e.g., $0.5 \%$ bupivacaine into the subarachnoid space. Other medications like opioids and clonidine can be added to improve the quality of the block [1].

Even though this procedure is relatively safe, there are reports of major complications that have been attributed to human errors like lack of vigilance, wrong labeling or presentation of syringes and ampoules, or underestimation of the double-checking concept [2]. In our center, 4000 caesarean sections are done in a year with $85 \%$ under spinal anesthesia. This is the first report of uncontrollable jerking of the lower limbs followed by hypertension and arrhythmias following administration of spinal anesthesia.

\section{Description of Case}

A 27-year-old patient Gravida 2 Para 1 presented around 7.00 am for an elective Caesarean section on account of a previous caesarean section.

The patient was brought to the obstetric theater at around 7.00 am for an elective caesarean $\operatorname{section}(\mathrm{C} / \mathrm{S})$ on account of a previous $\mathrm{C} / \mathrm{S}$. She was a 27 -year-old midwife Gravida 2 Para 1 alive. The patient had been to the

"Corresponding author. anesthetic clinic and had been cleared for surgery. She was an ASA class 1 patient.

Spinal anesthesia was done with the patient in the sitting position at the L4-L5 interspace, using a 25-gauge needle. The nurse anesthetist on duty gave an ampoule of $4 \mathrm{~mL}$ of $0.5 \%$ hyperbaric bupivacaine to the student anesthetist who was doing the procedure. After injection of the bupivacaine, the patient's blood pressure remained stable. However, the patient could partially lift both legs five minutes after the spinal. There were no other complaints and the nurse anesthetist thought by the time the surgeon was ready to the block would be working.

After scrubbing and draping when the surgeon tested the spinal block, the patient felt pain. At this time the patient had started having myoclonic seizures limited to the lower limbs and the abdomen. The patient had at this moment become very anxious her BP had shot to $175 / 95$ $\mathrm{mmHg}$ and therefore the nurse anesthetist decided to convert the spinal to general anesthesia. He could not explain what was causing the myoclonic seizure and the hypertension.

General anesthesia was induced with thiopentone 450 $\mathrm{mg}$ followed by suxamethorium $100 \mathrm{mg}$ after which the patient was successfully intubated.

The baby was delivered about $5 \mathrm{~min}$ after incision. APGAR Score at 1 st minute was 8/10. Syntocinon $10 \mathrm{iu}$ was given for muscle contraction followed by $100 \mu \mathrm{g}$ of fentany 1 for analgesia. The patient also received $1.2 \mathrm{~g}$ of Augmentin. 
After the baby was delivered the surgeon again observed the seizure but thought it was the patient moving because of light anesthesia. The nurse anesthetist assessed the depth of anesthesia and found it to be adequate and therefore assured the surgeon to continue with the surgery.

At the end of surgery which lasted about 30 minutes and theinhalational agent had been cut off, the myoclonic seizures had worsened, the patient could open the eyes but was restless and could not be extubated. She was therefore sent to the ICU for further management.

The patient was received in the ICU unconscious with Glasgow Coma Score of 3/15.

Pupils were equal and moderate in size. They reacted appropriately to light.

There were no obvious lateralaising signs. The patient however had multiple tonic seizures involving the lower limbs and the abdominal muscles.

RBS checked was $7.4 \mathrm{mmol} / \mathrm{l}$, temperature was $38.4^{\circ} \mathrm{C}$.

The patient was given thiopentone for immediate control of the seizures and was put on a ventilator for ventilatory support.

The anesthesiologist in the ICU suspected eclampsia and possible wrong injection into the subarachnoid space. CT scan of the head and the lumbosacral region taken was normal. All her laboratory investigations KFT, LFT, TFT and FBC were normal.

A check at the theater where the operation was done revealed that there was a left over tranexamic acid(TXA) on the anesthesia drug trolley. The ampoule looked similar to the bupivacaine ampoule. The student nurse anesthetist who did the spinal confirmed it was the tranexamic ampoule that was given to him by the nurse anesthetist (Figure 1).

The patient's condition deteriorated with frequent convulsions despite the administration of anticonvulsants. She also developed tachyarrhythmias and suffered a

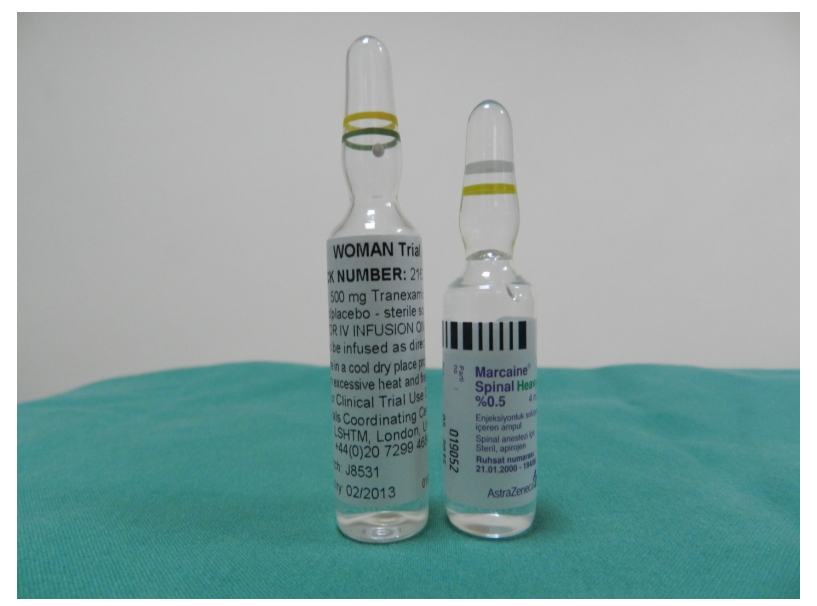

Figure 1. Picture showing ampoules of tranexamic acid and heavy bupivacaine. cardiac arrest 24 hrs after admission for which she was resuscitated. 12 hours later she developed ventricular tachycardia and eventually ventricular fibrillation which was refractory to resuscitation. The patient was pronounced dead less than 48 hours after admission to the ICU. A post mortem was requested but the relatives declined.

\section{Discussion}

Accidental injection of intrathecal tranexamic acid is not uncommon. Firouzeh et al. [3] reported of a case of an obstetric patient who accidentally was given tranexamic acid intrahecally. 3 minutes after the injection, the patient beguntossing and turning and complained of sharp painin the lower abdomen. She became dysphoric and complained of dizziness. General anesthesia was induced and the baby was delivered. Post operatively the patient developed tachyarrhythmias he was also noted to have severe jerking motions in her lower extremeties consistent with seizure. The patient had cardiac arrest which was refractory to resuscitation.

De Leede-Van der Maarl et al. [4] reported a case of a 68-year-old man who accidentally received an intrathecal injection of $50 \mathrm{mg}$ tranexamicacid. Immediately after the administration of the drug, he developed status epilepticus. The outcome was complicated, with hypotonic paresis of all four extremities, which resolved but resulted in residual bilateral peroneal palsy. In the case reported by Yeh et al. [5] generalized convulsions and refractory ventricular fibrillation after intrathecal administration of $500 \mathrm{mg}$ of tranexamic acid was associated with fatal outcome. In two others case reports, intrathecal injection of a dose of $150 \mathrm{mg}$ of tranexamic acid lead to a poor issue in one case because of a refractory ventricular fibrillation.

The exact mechanism by which TXA acid induces convulsion or ventricular arrhythmias is unknown. However high doses of TXA would cause massive sympathetic discharge leading to hypertension and subsequent ventricular arrhythmias as in our case [6]. Furtmuller et al. also reported an antagonistic action of TXA at gamma amino butyric acid-A (GABA) receptors explaining a lowering of the seizure threshold by TXA [7]. Our patient received an intrathacal injection of $200 \mathrm{mg}$ of tranexamic acid leading to clonic seizures, tachycardia and death in less than 48 hours.

At the time, this incident occurred there was an ongoing study on tranexamic acid for the management of Post partum Haemorrhage by the O\&G Department in our hospital code named "WOMAN TRIAL". This probably explains why the drug found its way on the anesthesia drug trolley.We have since instituted a policy not to keep such unusual non anestthetic drugs on the anesthesia drug trolley. 


\section{Conclusions}

In the literature, cases that have been reported about accidental intrathecal injection of tranexamicacid resulted from confusion between tranexamic acid and $0.5 \%$ bupivacaine ampoules. This was because the two ampoules were similar in appearance.

We recommend that critical drugs like the drugs used for spinal anesthesia have unique appearance and package so the possibility of confusion is remote. At the same time the anesthetist must check the ampoule label precisely and stick to the double checking concept.

Finally, due process must be followed irrespective of the status of the patient. In this case, the patient was a staff, who was coming for an elective caesarean section, no list had been sent to the anesthetist and even the surgeon was not the one on duty. We believe the nurse anesthetist who is a junior staff was rushed to do this case. He had been working for 11 hours and would obviously be tired.

\section{REFERENCES}

[1] H. Hyderally, "Complications of Spinal Anesthesia," Mo- unt Sinai Journal of Medicine, Vol. 69, No. 1-2, 2002, pp. 55-56.

[2] J. B. Cooper, R. S. Newbower and R. J. Kitz, "An Analysis of Major Errors and Equipment Dailures in Anesthesia Management: Considerations for Prevention and Detection," Anesthesiology, Vol. 60, No. 1, 1984, pp. 34-42. doi:10.1097/00000542-198401000-00008

[3] F. Veisi, B. Salami and G. Mohseni "Accidental Intrathecal Injection of Tranexamic Acid in Caesarean Section: A Fatal Medication Error,” APSF Newsletter Spring, 2010.

[4] M. G. de Leede-van der Maarl, P. Hilkens and F. Bosch, "The Epileptogenic Effects of Tranexamic Acid," Journal of Neurology, Vol. 246, No. 9, 1999, pp. 843-845. doi:10.1007/s004150050466

[5] H. M. Yeh, H. P. Lau, P. L. Lin, W. Z. Sun and M. S. Mok, "Convulsion and Refractory Ventricular Fibrillation after Intrathecal Administration of a Massive Dose of Tranexamic Acid," Anesthesiology, Vol. 98, No. 1, 2003, pp. 270-272. doi:10.1097/00000542-200301000-00042

[6] R. Furtmuller, M. G. Schlag, M. Berger, et al., "Tranexamic Acid, a Widely Used Antifibrinolytic Agent, Causes Convulsion by a $\gamma$-Aminobutyric Acid $_{\mathrm{A}}$ Receptor Antagonistic Effect," Journal of Pharmacology and Experimental Therapeutics, Vol. 301, No. 1, 2002, pp. 168-173. doi:10.1124/jpet.301.1.168 